\title{
Análise do som em Dots de Norman McLaren
}

\author{
Sound Analysis in Dots by Norman McLaren
}

\section{Maria Kauffmann \\ Eduardo Simões dos Santos Mendes \\ Universidade de São Paulo}

\begin{abstract}
Resumo: Este trabalho analisa as relações som-imagem no curta-metragem de animação Dots (1940, dir. Norman McLaren) a partir da descrição espectromorfológica de seus objetos sonoros. Usamos aqui a proposta de notação gráfica de Thoresen (2007), baseada nas categorias tipomorfológicas de Schaeffer (1966). Norman McLaren (1914-1987) foi um cineasta Escocês-Canadense que dedicou grande parte de sua carreira ao campo da animação experimental. Desenvolveu diversas técnicas de produção cinematográfica, dentre as quais destacamos seus procedimentos de sonorização sintética através da intervenção direta na película entre as décadas de 1940 e 1970. Categorizamos o trabalho de som sintético de McLaren entre som desenhado, som riscado e som animado e descrevemos suas características sonoras com o apoio de espectrogramas.
\end{abstract}

Palavras-chave: som ótico; intervenção direta em película; animação; espectromorfologia; som sintético

Abstract: This article analyzes the sound-image relations on the animated short-film Dots (1940, dir. Norman McLaren) through spectromorphological description of its sound objects. Here we use the graphical notation propositions on Thoresen (2007), which are based on Schaeffer's (1966) typomorphological categories. Norman McLaren (1914-1987) was a scottish-canadian filmmaker that dedicated most of his career to the experimental animation field. He developed several film production techniques, amongst which we highlight his sound synthesis techniques through direct intervention on film strips between the 1940's and 1970's. We categorize McLaren's synthetic sound works between drawn-on-film sound, scratched-on-film sound and animated sound, and describe its characteristics with the support of spectrograms.

Keywords: optical sound; animation; cameraless animation; spectromorfology; synthetic sound 
MUSICA THEORICA Revista da Associação Brasileira de Teoria e Análise Musical 2019, v. 4, n. 2, p. 208-228 - Journal of the Brazilian Society for Music

\section{Introdução}

Este trabalho é uma aplicação de metodologias desenvolvidas no campo da música eletroacústica na análise do fluxo sonoro de obras audiovisuais. Esta abordagem utilizada como uma ferramenta que não se referencia pela diegese e distinção entre diálogo, música e ruído.

O esforço de notação gráfica e descrição dos sons decorre de um exercício de escuta reduzida, proposto originalmente por Pierre Schaeffer em seu Tratado dos Objetos Musicais, de 1966. Neste modo de escuta, apreendemos os sons por suas características intrínsecas, pouco importando as relações com o real, causa e sentido que eles possam conter.

Schaeffer desenvolve um diagrama tipomorfológico das características do objeto sonoro. No eixo vertical, relaciona o conteúdo espectral, e, no horizontal, o desenvolvimento energético dos sons no tempo e suas durações. Isto serve de base para autores posteriores como Smalley (1997), que cunha o termo "spectromorphology" (espectromorfologia). Thoresen (2007) considera esta a palavra mais adequada na língua inglesa para designar o campo de estudos da escuta inaugurado por Schaeffer.

Os símbolos usados neste trabalho derivam de uma adaptação, feita por Thoresen, da tipomorfologia e suas categorias. O autor considera a proposta original de Schaeffer pouco prática para uso em análises, em parte devido à sua representação por letras. Os símbolos de Thoresen permitem uma maior aglutinação de sentidos, muitas vezes icônicos, como no caso das linhas descontínuas para objetos iterados, por exemplo.

Neste trabalho, analisamos o curta-metragem Dots (1940), que inaugura a experimentação do cineasta Norman McLaren com a síntese sonora a partir de intervenções diretas na pista de som ótico da película cinematográfica.

A análise de Dots foi feita no software Acousmographe, ${ }^{1}$ desenvolvido pelo Groupe de Recherches Musicales (GRM), com auxílio do plugin Aural Sonology e a fonte Sonova, ${ }^{2}$ desenvolvida por Karl Andreas Hedman. Espectrogramas adicionais foram gerados no software Sonic Visualiser, ${ }^{3}$ desenvolvido pelo Centre for Digital Music da Queen Mary, University of London. Todos os

\footnotetext{
${ }^{1}$ Disponível para download em: https://inagrm.com/en/showcase/news/203/acousmographe

2 Disponível para download em: http://www.spectromusic.com/

${ }^{3}$ Disponível para download em: https://www.sonicvisualiser.org/
} 
espectrogramas foram gerados a partir de vídeos de extensão .mp4, formato AVC, extraídos de uma caixa de DVD da obra de McLaren disponível comercialmente no Brasil.

\section{Sobre Norman McLaren}

Norman McLaren (1914-1987) foi um cineasta Escocês-Canadense que atuou entre as décadas de 1930 e 1980 no campo do curta-metragem de animação experimental. Passou a maior parte de sua carreira ligado ao National Film Board of Canada (NFB), instituição estatal responsável pela produção e distribuição de filmes de cunho não-comercial, onde estruturou e chefiou a Unidade de Animação entre os anos de 1943 e 1984. Ao longo destas décadas, pôde contar com os recursos do NFB para o desenvolvimento e aprimoramento de inúmeras técnicas de animação e procedimentos fotoquímicos não-convencionais, dentre os quais a animação quadro-a-quadro de seres humanos, chamada de pixillation, e a animação por intervenção direta na película virgem se destacam. Neste período, também foram sistematizadas suas experiências na área de síntese sonora pela manipulação da pista de som ótico do rolo de filme.

\section{Os três métodos de síntese sonora de Norman McLaren}

O som ótico é o padrão que foi estabelecido pela indústria cinematográfica para gravação e reprodução de som em cópias de filmes sonoros desde o final da década de 1920, utilizado até hoje em salas de cinema com projeção analógica. A gravação de uma pista de som ótico é o registro da luz que atravessa uma estreita abertura modulada pelo sinal elétrico do microfone. Na leitura desta pista pelo projetor, a célula fotoelétrica, que transforma luz em eletricidade/sinal sonoro, é sensibilizada por uma lâmpada, cuja luminosidade é modulada pelas inscrições gráficas na película. O som ótico no cinema é, portanto, uma relação de luminosidades controlada por uma área estreita ao lado do fotograma. 
MUSICA THEORICA Revista da Associação Brasileira de Teoria e Análise Musical 2019,

v. 4, n. 2, p. 208-228 - Journal of the Brazilian Society for Music

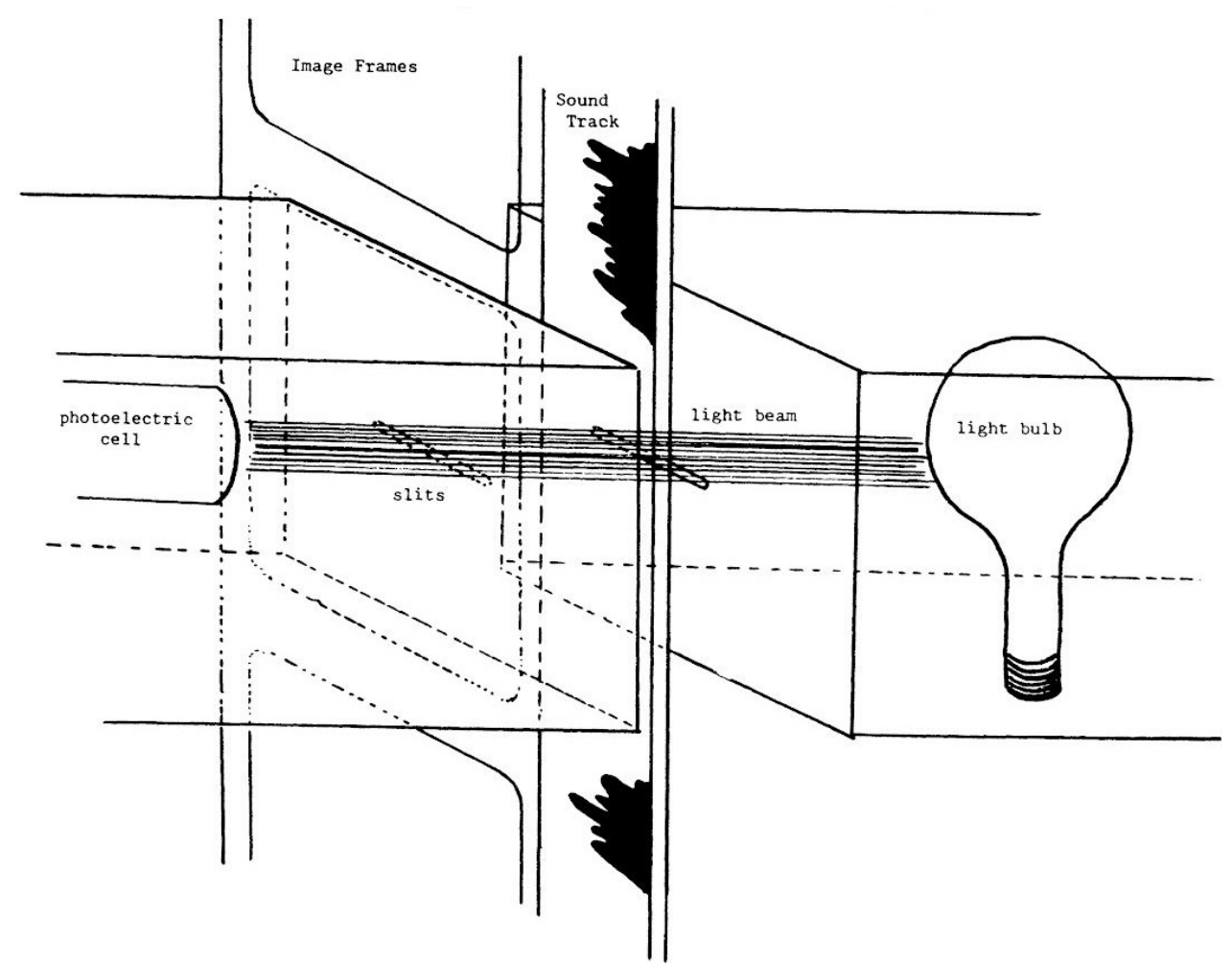

Figura 1: Diagrama da cabeça de leitura de som ótico em projetor de cinema (Fonte: James, 1986)

McLaren deixou registradas extensas notas técnicas sobre a feitura de cada um de seus filmes. De caráter bastante didático, eram distribuídas pelo cineasta a quem entrasse em contato com interesse e curiosidade pelos bastidores de seus filmes. O material foi revisado por ele em 1984, três anos antes de sua morte, compilado pelo NFB e hoje disponível online, no site da instituição. ${ }^{4} \mathrm{~A}$ partir destes escritos, podemos dividir sua produção de som sintético em três métodos: som desenhado na película transparente, som riscado na película preta e o "som animado" com cartões.

Os dois primeiros métodos são baseados na intervenção direta na área da pista de som da película $35 \mathrm{~mm}$, parecido com o que McLaren já fazia com a imagem desde a década de 1930, a chamada cameraless animation (animação sem câmera). Este tipo de sonorização foi sua primeira técnica de síntese desenvolvida e torna-se mais rara no decorrer de sua filmografia devido, principalmente, à dificuldade de manipulação dos materiais.

\footnotetext{
${ }^{4}$ Disponível para download em: http://www3.nfb.ca/archives_mclaren/notech/NT_EN.pdf
} 
Segundo o cineasta, era muito difícil trabalhar com o som em filme transparente devido à sujeira que este acumulava, que se transformava em ruído na leitura do som ótico. O som desenhado em película transparente aparece em apenas três obras, realizadas entre 1939 e 40: Scherzo, Dots e Loops. Em seus filmes seguintes, McLaren preferia trabalhar com película preta, riscando a emulsão e gerando sons de caráter percussivo que podem ser ouvidos em Rythmetic (1956) e Mosaic (1965).

O terceiro método foi batizado pelo cineasta de animated sound (som animado), pois empregava um procedimento comum de animação da época, a câmera suspensa sobre uma mesa (chamada de table-top) capturando as imagens, e agora também sons, quadro-a-quadro. McLaren fotografava, na área da pista de som, uma série de cartões com padrões gráficos de ondas quadradas, que seriam lidos no projetor como notas da escala cromática. O som animado foi empregado na sonorização de filmes como Neighbours (1952) e Synchromy (1971). Neste segundo, os cartões da pista de som também compõem integralmente a imagem, sendo uma boa ilustração do funcionamento deste sistema.

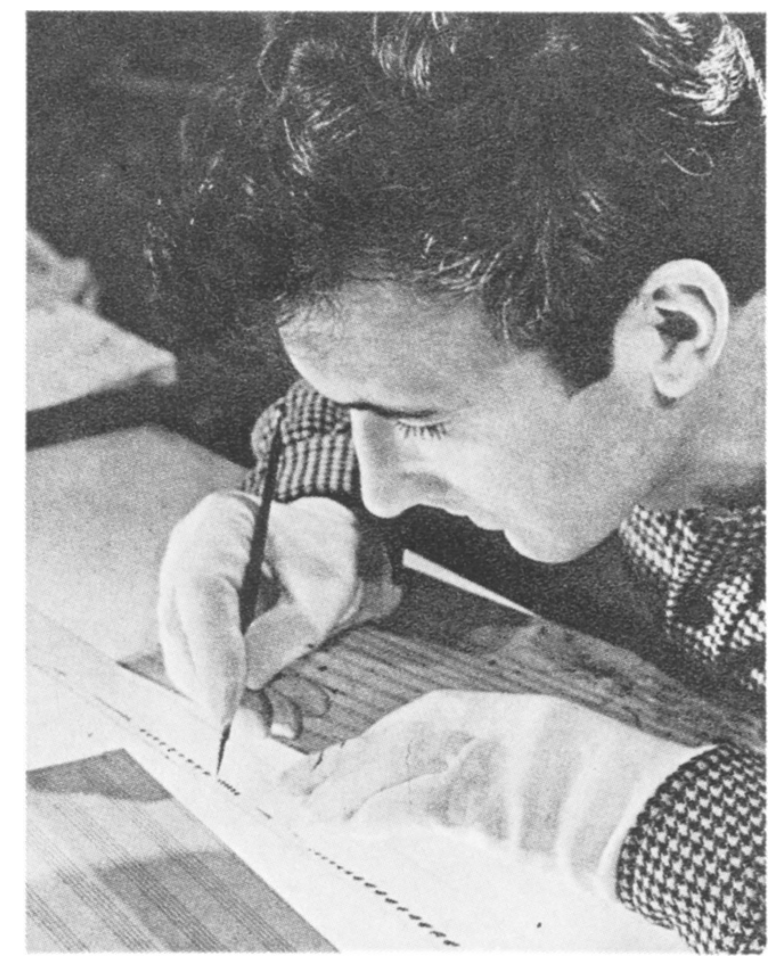

Figura 2: Norman McLaren trabalhando em uma pista de som de intervenção direta em película transparente (Fonte: The Handwritten Sound Track 1968, p. 114) 
MUSICA THEORICA Revista da Associação Brasileira de Teoria e Análise Musical 2019, v. 4, n. 2, p. 208-228 - Journal of the Brazilian Society for Music Theory and Analysis @ TeMA 2019 - ISSN 2525-5541

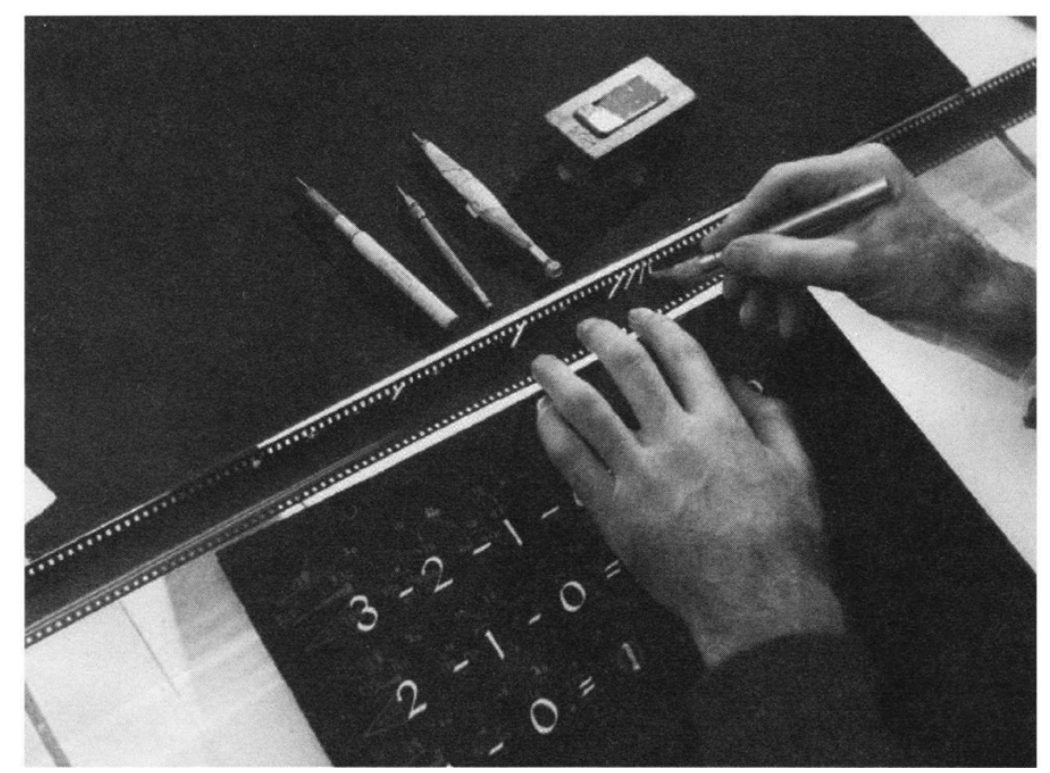

Figura 3a: Norman McLaren trabalhando na trilha de Rythmetic, som de intervenção direta na película preta (Fonte: Russett; Starr 1976, p. 167)

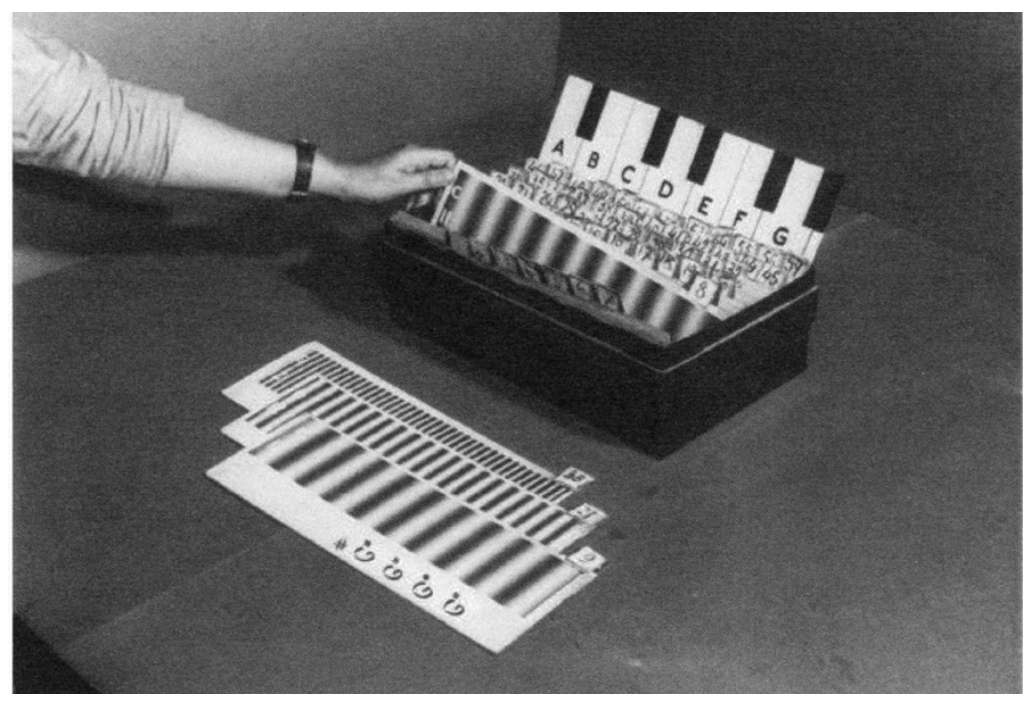

Figura 3b: Cartões de ondas quadradas utilizados no som animado (Fonte: Russett; Starr 1976, p. 167)

\section{Características gerais do som ótico sintético}

Apesar de modos de produção distintos, estes sons sintéticos de McLaren têm diversas características em comum devido ao suporte da película e as tecnologias da época. Todas estas trilhas compostas por métodos sintéticos são monofônicas, já que a estereofonia no cinema passa a ser corrente apenas em meados da década 1970 com a adoção do sistema Dolby SVA (stereo variable area), 
e têm uma resposta de frequência máxima até a região dos $10 \mathrm{kHz}$, próxima do limiar do som ótico em filme de bitola $35 \mathrm{~mm}$ deste período.

O som de intervenção direta e o som animado têm um caráter marcadamente iterativo, não sendo comuns sons de sustentação muito longa. No caso do método dos cartões, isto se dá pelo difícil alinhamento dos mesmos ao longo de muitos fotogramas, o que causa um ruído de fundo de 24 iterações por segundo ao qual McLaren se refere como um "ronronar" (purr); enquanto o som de intervenção direta é todo baseado em modulação da luminosidade por riscos iterativos.

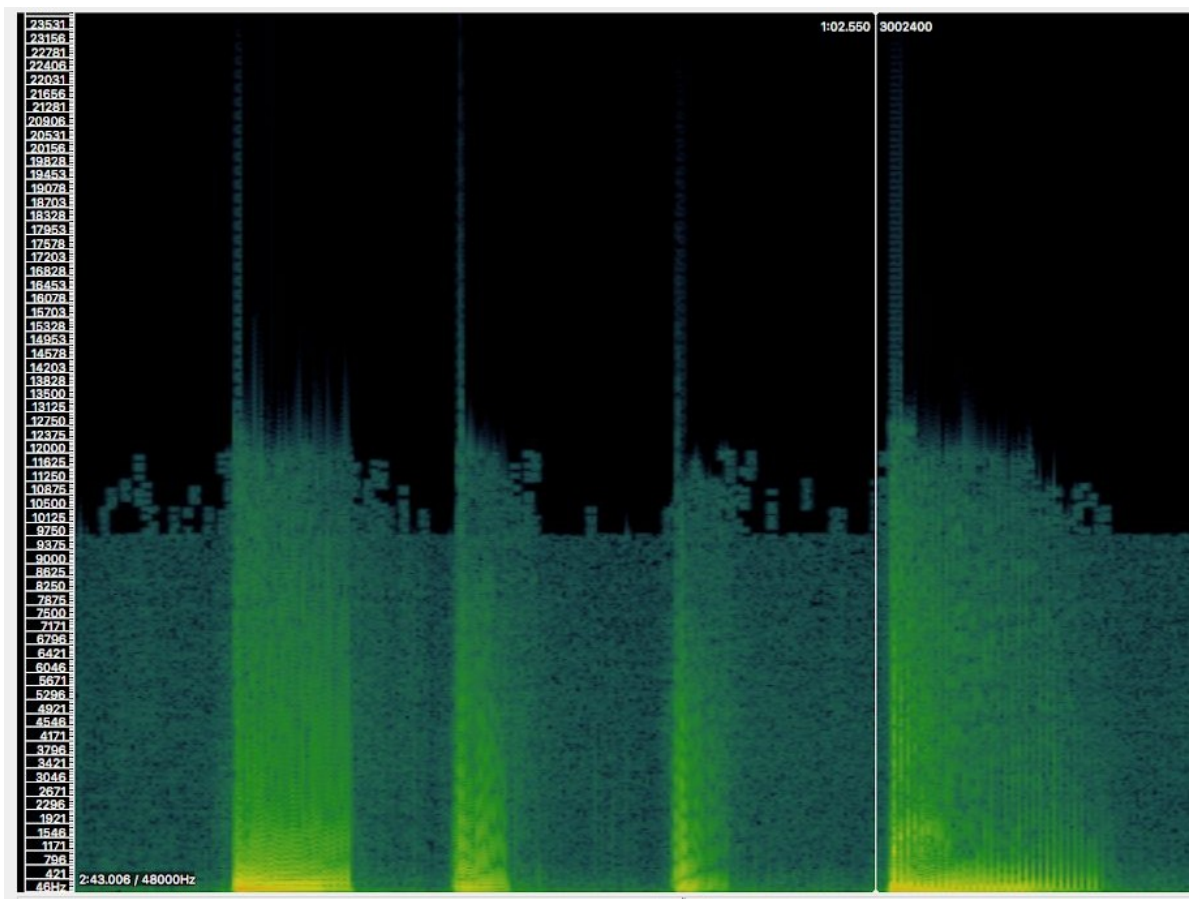

Figura 4: Espectrograma de Loops, som desenhado em película transparente 
MUSICA THEORICA Revista da Associação Brasileira de Teoria e Análise Musical 2019, v. 4, n. 2, p. 208-228 - Journal of the Brazilian Society for Music Theory and Analysis@ TeMA 2019 - ISSN 2525-5541

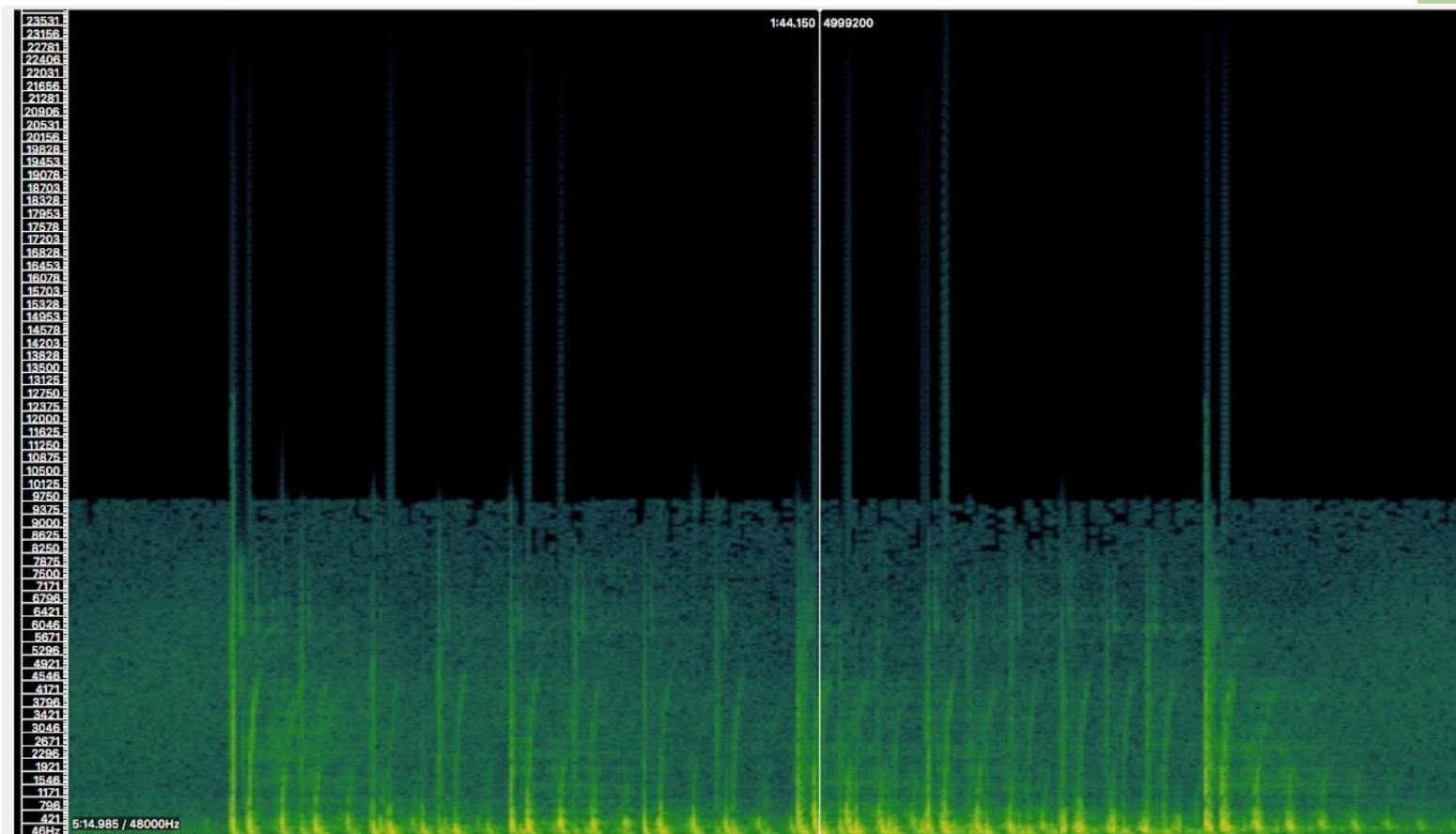

Figura 5: Espectrograma de Blinkity Blank, som riscado em película preta

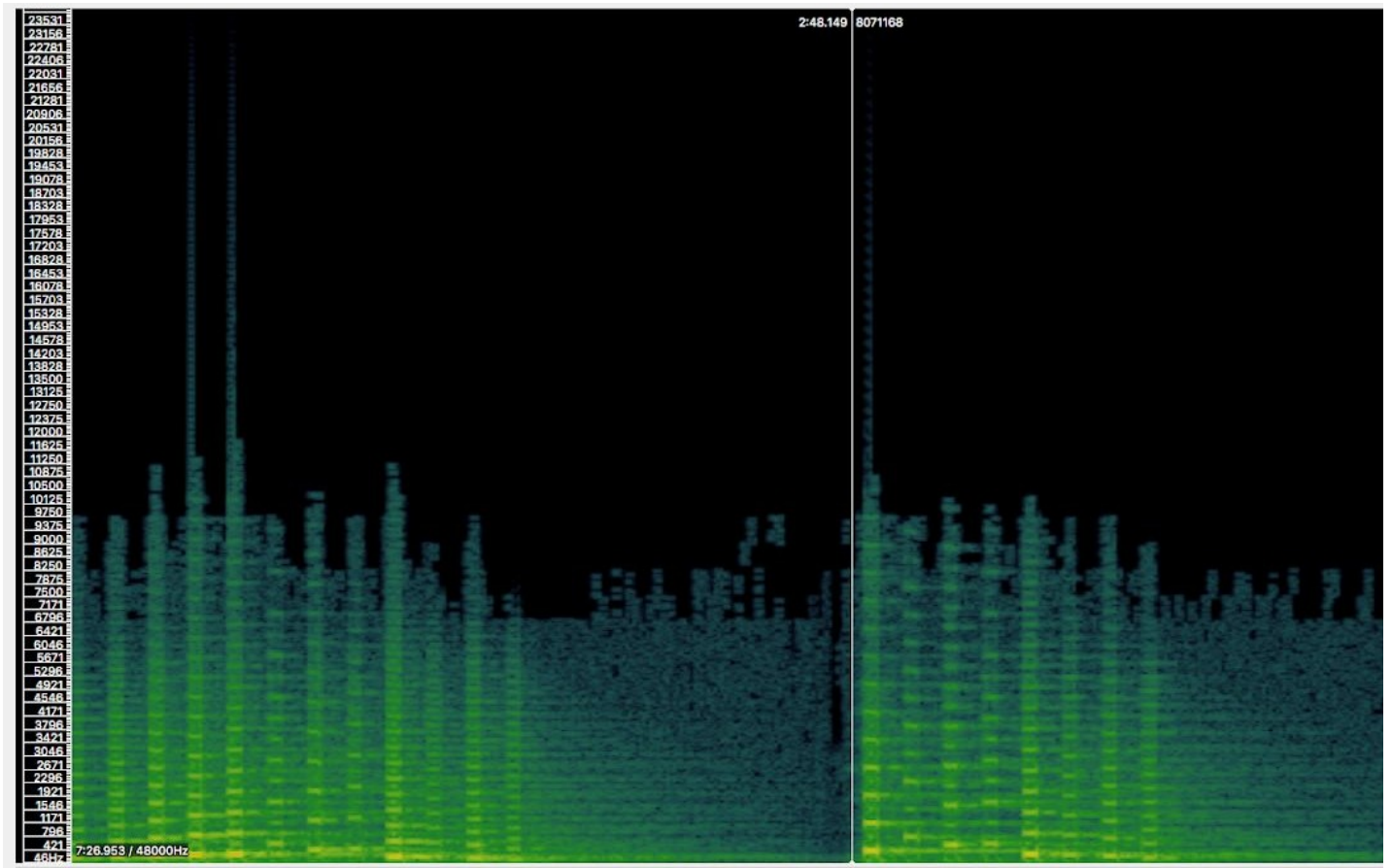

Figura 6: Espectrograma de Synchromy, som animado 


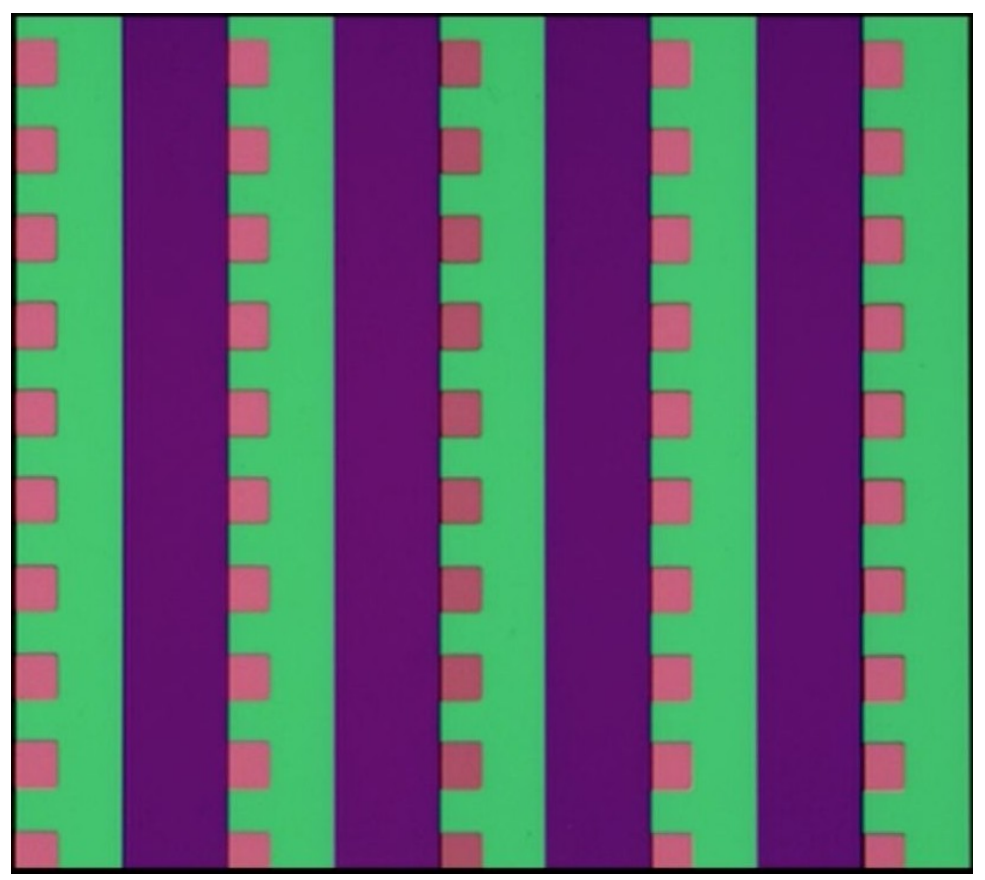

Figura 7: Fotograma de Synchromy, correspondente ao espectrograma acima

O pós-processamento dos sons óticos sintéticos torna-se mais comum no decorrer da carreira de McLaren, conforme as tecnologias de mixagem se aprimoram. Os sons desenhados de seus primeiros filmes de 1940 mantém o caráter seco, sem reverberação, próprios do som sintético "bruto". A partir de meados da década de 1950 temos um trabalho de refinamento destes sons durante o processo de mixagem, com o uso de equalizadores $\mathrm{e}$ compressores/expansores, além de câmara de reverberação. Temos também a interação de sons sintéticos com sons instrumentais, como em Blinkity Blank (1956).

A trilha de Mosaic (1965) é composta por som riscado com diferentes graus de reverberação. Esta reverberação sugere espacialidade, conferindo ao som sintético o que Chion (2009, p. 244) chama de índices de materialidade sonora (materializing sound indices): "[...] qualidades de um som que dirigem nossa atenção às naturezas físicas de sua fonte" ${ }^{\prime 5}$

\footnotetext{
5 "[...]qualities of a sound that direct our attention to the physical natures of its source."
} 


\section{Ferramentas de análise audiovisual}

Uma das formulações de Michel Chion em seu livro Audio-vision é a de que, no cinema, não existe a "trilha sonora" como um espaço do som com coesão interna. Para o autor, o contrato audiovisual pressupõe que as relações verticais entre som e imagem são muito mais fortes do que as relações horizontais de sons entre si. Ademais, o fato de o fluxo sonoro não ser quantificável em unidades de rupturas definidas subordina a banda de áudio aos planos da imagem (Chion 1994).

O fluxo sonoro, em relação à imagem, organiza-se no tríptico em quadro (onscreen) - fora de quadro (offscreen) - não diegético (non-diegetic), reproduzido abaixo:

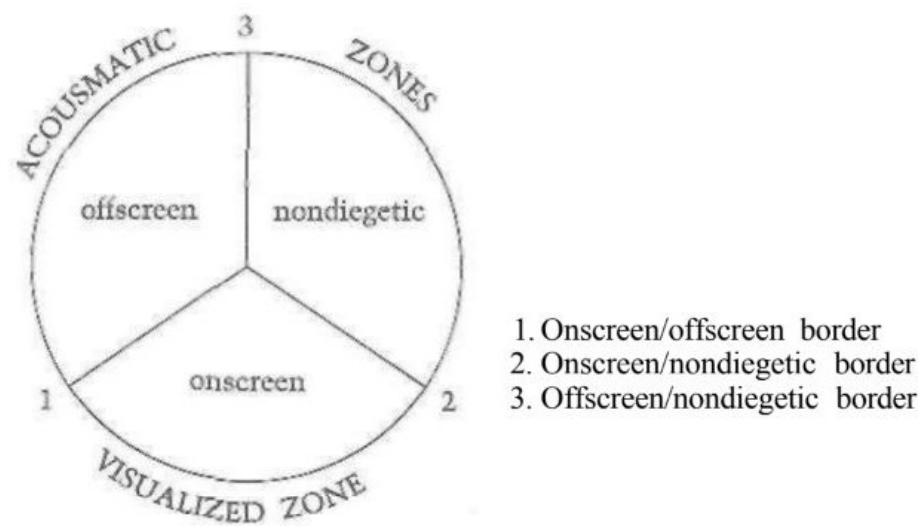

Figura 8: Áreas de atuação dos sons em relação à imagem e diegeses (Fonte: Chion 1994, p. 74)

Pressupõe-se que todo som cuja fonte sonora é visível, dentro de quadro, faz parte da diegese (mundo interno da narrativa), enquanto os sons acusmáticos se dividem entre fora de quadro diegéticos (como ambiências, por exemplo) e não diegéticos (como música de fundo e voz de narração, na maioria dos casos). Embora esta divisão seja uma ferramenta bastante útil para a análise de relações audiovisuais em filmes narrativos, essa classificação não se adequa facilmente à obra mais abstrata de McLaren.

A questão do som em quadro/fora de quadro em filmes de McLaren tem relação com os efeitos de sincronia/dessincronia que o cineasta trabalha. Um conceito que pode ser bastante usado é o de síncrese - neologismo cunhado pelo próprio Chion, da fusão entre "sincronia" e "síntese" - que é a percepção, pelo espectador, de eventos simultâneos de imagem e som como parte do mesmo fenômeno, não importando o quão distintos em natureza estes sejam. Para o 
autor, a síncrese permite que sons gravados em estúdio e pós-sincronizados, chamados de foley, sejam aceitos no contrato audiovisual - como os sons nãonaturalistas que acompanham socos em filmes de luta, por exemplo (Chion 1994).

A síncrese é a base da relação imagem-som em Dots e Loops. Valendo-se de uma sincronia estreita, facilitada pela execução simultânea de imagem e som pelo método de intervenção direta na película, McLaren associa as diferentes formas abstratas aos objetos sonoros sintéticos, transformando-as em fontes sonoras. Os movimentos dos pontos e das linhas têm uma certa qualidade antropomórfica, que fica clara quando os comparamos com os movimentos em filmes como Mosaic ou Spheres (1969), mas a falta de índices de materialidade sonora dos sons que os acompanham reforça o caráter abstrato destas imagens.

É corrente, tanto entre acadêmicos quanto técnicos, a divisão de elementos do fluxo sonoro no cinema entre diálogos, ruído e música. Na obra de McLaren não existem diálogos

- o que torna-se uma piada em Opening Speech (1961), exibido na abertura do I Festival Internacional de Cinema de Montreal, em que o cineasta não consegue proferir suas palavras por conta de um microfone animado rebelde. $\mathrm{O}$ uso de foley também é raro.

McLaren trabalha na maior parte do tempo com elementos que podem ser considerados música: de fundo, como em Hen Hop (1943); articulações sonoras em que música e ruído formam uma fronteira fluida, como nas passagens de som sintético em Blinkity Blank; ou pontuações musicais sincronizadas com gestos e movimentos, muito presentes nas cenas de luta em Neighbours, por exemplo. Este último utiliza uma técnica de escrita de música para filmes chamada mickeymousing, termo um pouco pejorativo que faz referência ao método de composição musical das trilhas de animações das décadas de 1930 e 40.

Mickeymousing consiste em seguir a ação visual em sincronia com trajetórias musicais (subida, descida, zigzagues) e pontuações intrumentais de ações (batidas, quedas, portas fechando) (Chion 1994, p. 121). ${ }^{6}$

Este método, Chion aponta, é criticado pela redundância entre imagem e som, mas tem a função de auxiliar na compreensão de movimentos rápidos. McLaren declara que a primeira vez que escapou do mickeymousing foi na

\footnotetext{
6 "Mickeymousing consists in following the visual action in synchrony with musical trajectories (rising, falling, zigzagging) and instrumental punctuations of action (blows, falls, doors closing)."
} 
MUSICA THEORICA Revista da Associação Brasileira de Teoria e Análise Musical 2019, v. 4, n. 2, p. 208-228 - Journal of the Brazilian Society for Music

dessincronia de Mosaic, já ao final de sua carreira (Mclaren, in Mcwilliams, 1991). A trilha mickeymousing de Dots é fundamental na percepção das colisões de pontos aos 0:01:56, por exemplo.

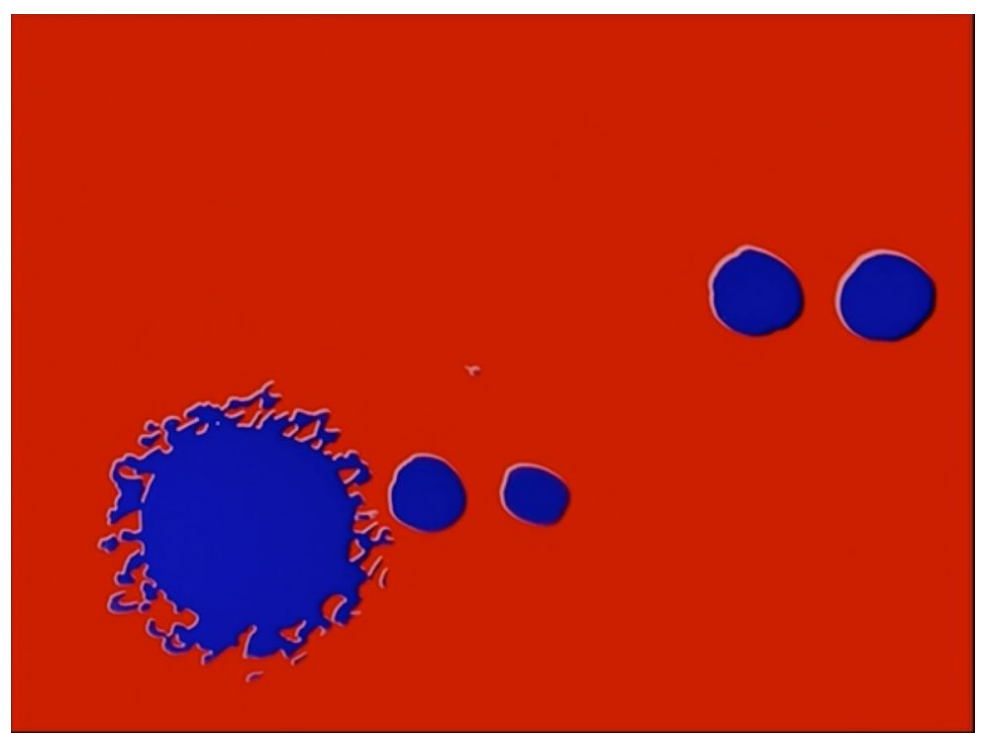

Figura 9: Fotograma de Dots, aos 0:01:56

A espectromorfologia é uma excelente ferramenta para a apreensão e descrição dos objetos sonoros sintéticos de McLaren, bem como para um melhor embasamento de uma taxonomia mais precisa de suas técnicas de produção e seus efeitos, para além de suas notas técnicas.

\section{Dots: Contexto de Produção}

Dots é um filme do começo da carreira de McLaren, realizado na época em que morou em Nova York, entre 1939 e 40, antes de estabelecer-se no Canadá. Sua produção neste período era feita de maneira privada e artesanal, por meio da animação por intervenção direta, e tinha poucos recursos e circulação. A partir de uma encomenda do Museu de Pintura Não-Objetiva, hoje Museu Guggenheim, McLaren consegue financiamento para a produção de seus dois principais curtas-metragens desta fase, Dots e Loops, de 1940.

Dots e Loops são filmes abstratos, feitos a partir de animação direta na película. A escolha da técnica era adequada aos exíguos recursos de produção que o cineasta dispunha. McLaren realizou dois curtas-metragens apenas com um rolo de filme transparente, pincel, tinta e uma traquitana adaptada em uma mesa enroladeira, projetada por ele mesmo. 
A partir das notas técnicas que o cineasta deixava escritas para a maioria de seus filmes, temos esquematizado como McLaren detinha algum controle sobre os sons que desenhava.

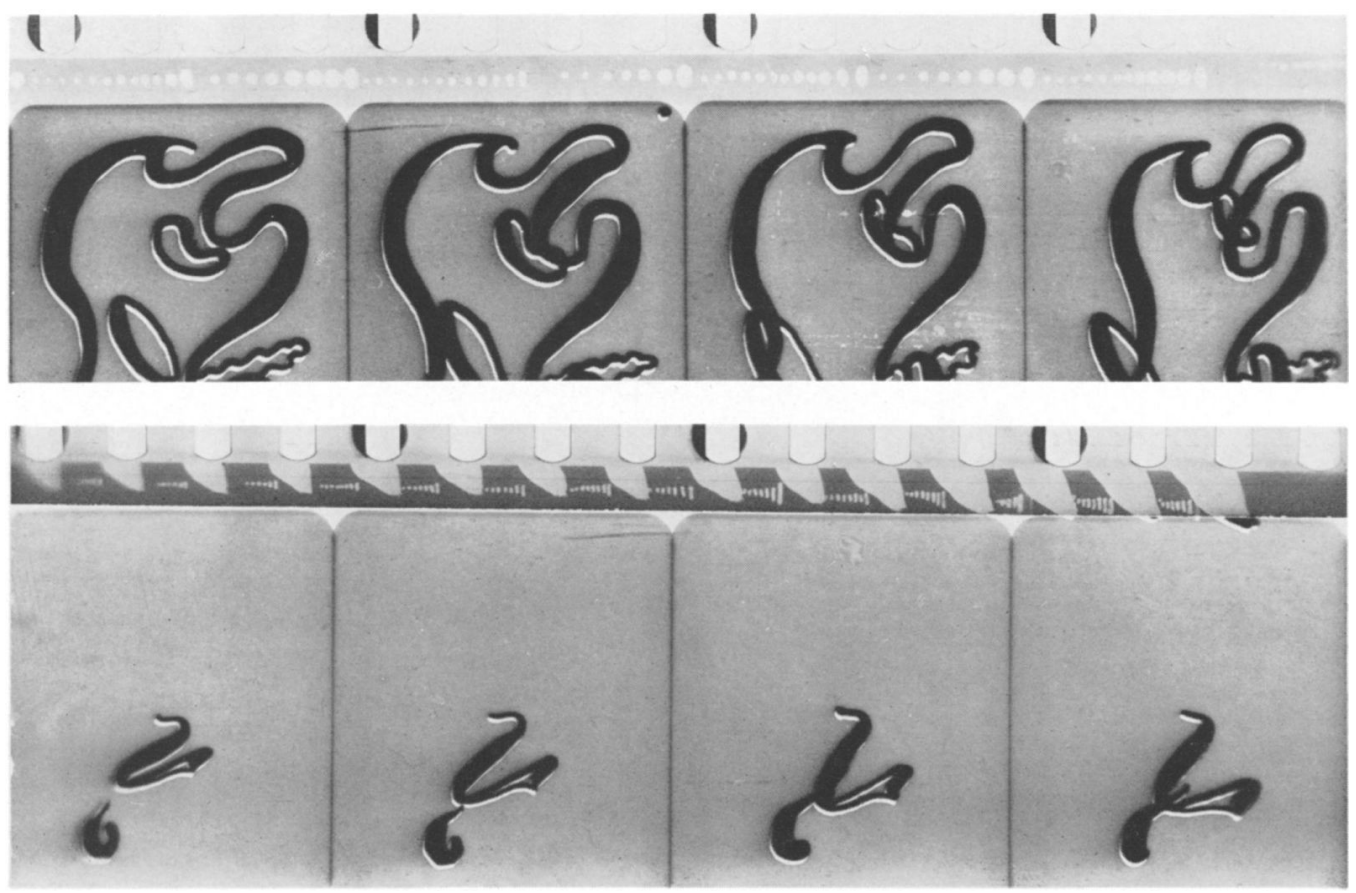

Figura 10: Fotogramas e pista de som de Loops (Fonte: The Handwritten Sound Track, 1968, p. 114) 7

\section{Apontamentos espectromorfológicos}

Com o apoio de espectrogramas de frequência e amplitude, foi feita uma proposta de notação de Dots no software Acousmographe e foram catalogados seus principais objetos sonoros. Importante ressaltar, de antemão, que a versão de Dots que temos acesso hoje não é a original de 1940, mas uma versão colorizada feita quando McLaren já trabalhava no NFB. Nos primeiros 53 segundos, temos uma cartela animada explicativa sonorizada com o som animado, acrescentada ao filme posteriormente. Optamos por incluir este trecho na análise para ilustrar a diferença de timbre entre o som animado e o som desenhado e ressaltar suas características estruturais semelhantes, principalmente na introdução. Nesta explicação das categorias identificadas na análise, não são traduzidos os termos do inglês para evitar maiores imprecisões. Ao longo do texto, procuro chamar de "formas" os elementos imagéticos e "objetos", os sonoros. 
The percusalve, sem1-musical ounds were made by painting and drawling with black India lak on clear $35 \mathrm{~mm}$. f1lm.

The sounds were placed in the sound track area adjacent to the plcture; In this case, on the same plece of f1lm on which the visual images were drawn. For synchronization during projection, the track was positioned 20 frames ahead of pleture it was intended to synchron1ze vith.

The sound track was later trangferred to normal variable area format for release.

Almost all the sounds were in the form of 'noteg' having an sbrupt beginning or sudden atrack, and tapering-off or decay, where posible, with an exponential shape or envelope:

SOURD TRAEK ARRA (ENIARGED) D D

Bach note was made up of aumber of strokes of the pen or brush. SD.TR. IIIII...

\section{CLICRS WITHOUT PRECISE PITCH}

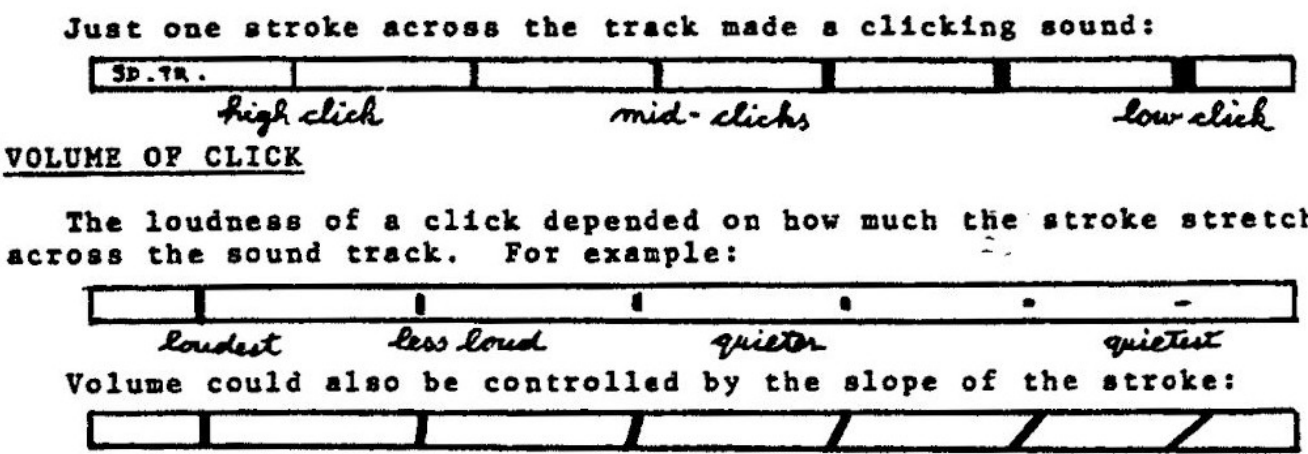

\section{SOUNDS WITH PITCH}

At least s1x strokes, If even1g spaced, were enough to wake a sound with a definlte pltch; the closer together the strokes vere the higher the pltch, the further apart, the lover the pltch.

For h1gh sounds a crow-qu111 pen was used:

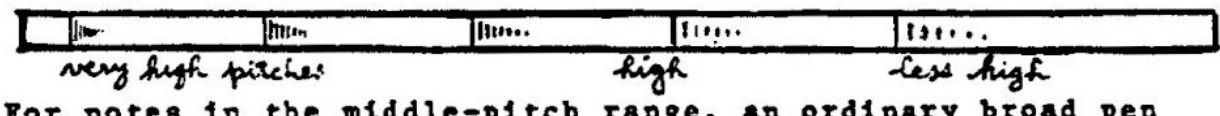

For notes in the middle-pltch range, an ordinary broad pen was used:

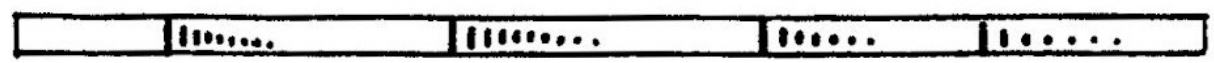

For deep notes narrow and broad brushes were used:

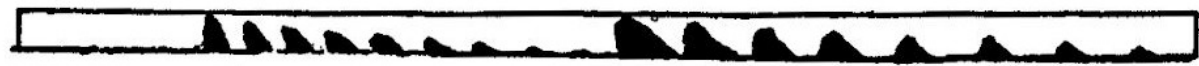

Figura 11: Notas técnicas para o som de Dots e Loops (Fonte: Dobson 2006, p. 106)

A partir de Thoresen (2007), foram atribuídos aos sons gerados pelo método animado (presentes até os 0:00:53) o símbolo de Pitched, por identificar 
visualmente as frequências de fundamental e harmônicos no espectrograma. Aos sons desenhados, foi designado o símbolo de Dystonic aberto. O objeto seria Dystonic porque possui espectro complexo com acúmulos de frequências em algumas regiões e aberto devido ao possível solfejo ligado à consoante $[p]$, não vocalizada. Entendo aqui o Dystonic como o equivalente ao que Smalley (1997) chamaria de "node", um ponto intermediário entre a nota e o ruído.

São nítidas as diferenças relativas de altura entre objetos sonoros, as quais McLaren detinha algum controle, segundo suas notas técnicas. Foi utilizada a escala de Spectral Brightness como uma maneira de representar a altura relativa destes objetos.

Todos os sons do filme foram identificados como impulso e iterados, não aplicando a categoria de sustentação a nenhum deles. As iterações nos objetos de maior duração são distinguíveis se os reproduzirmos em velocidades reduzidas. A partir da tabela abaixo, foram identificadas as velocidades, quase sempre na coluna do Regular, com algumas exceções a velocidades Oblíquas a partir dos 0:02:10, conforme os objetos ficam mais elaborados. Foi atribuído Gestural time às iterações nítidas na reprodução em velocidade normal; Ripple time às que necessitavam de reprodução a 50\% da velocidade e Flutter time às perceptíveis apenas na reprodução a $25 \%$ da velocidade.

\begin{tabular}{|c|c|c|c|}
\hline & Regular & Oblique & Irregular \\
\hline Gestural time & $\mathbf{R g}$ & $\mathbf{O q}$ & Ir \\
\hline Ripple time & $=$ & $\simeq$ & $\approx$ \\
\hline Flutter time & $\equiv$ & $\cong$ & $\approx$ \\
\hline
\end{tabular}

Tendencies :

accel.

rit.

\begin{tabular}{|l|l|l|}
\hline$\leqslant$ & $\approx$ & $\approx$ \\
\hline$\Rightarrow$ & $\Rightarrow$ & $\ni$ \\
\hline
\end{tabular}

Figura 12: Tipos de velocidades e durações (Fonte: Thoresen 2007) 
MUSICA THEORICA Revista da Associação Brasileira de Teoria e Análise Musical 2019, v. 4, n. 2, p. 208-228 - Journal of the Brazilian Society for Music

Podemos dividir o filme nas seguintes partes:

1) 0:00:00 - 0:00:52: Cartelas iniciais

2) 0:00:53 - 0:01:40: Introdução gradual dos timbres, principais formas e movimentos

3) 0:01:40 - 0:02:12: Desenvolvimento

4) 0:02:13 - 0:02:19: Conclusão

A seguir, comento algumas passagens.

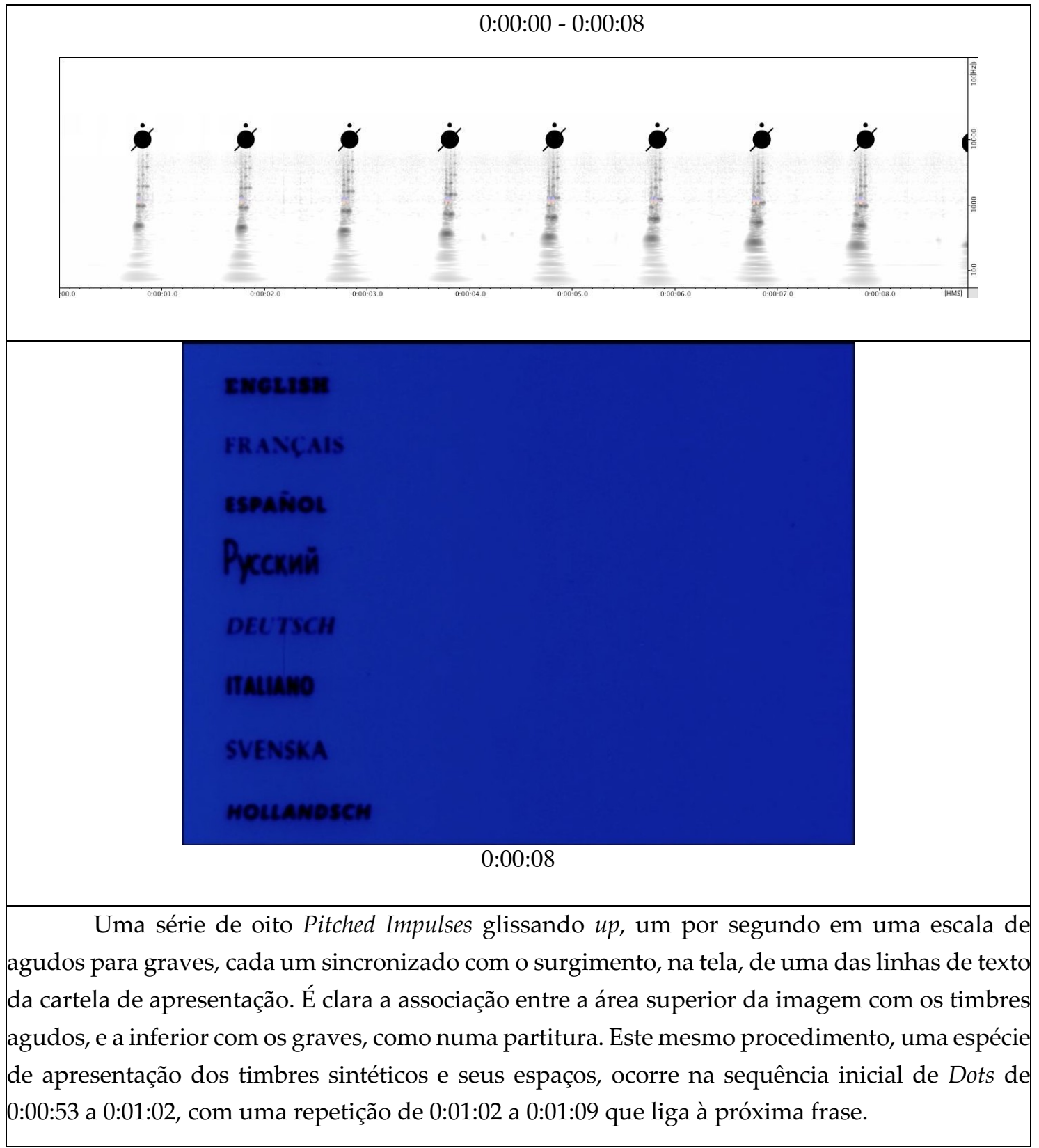




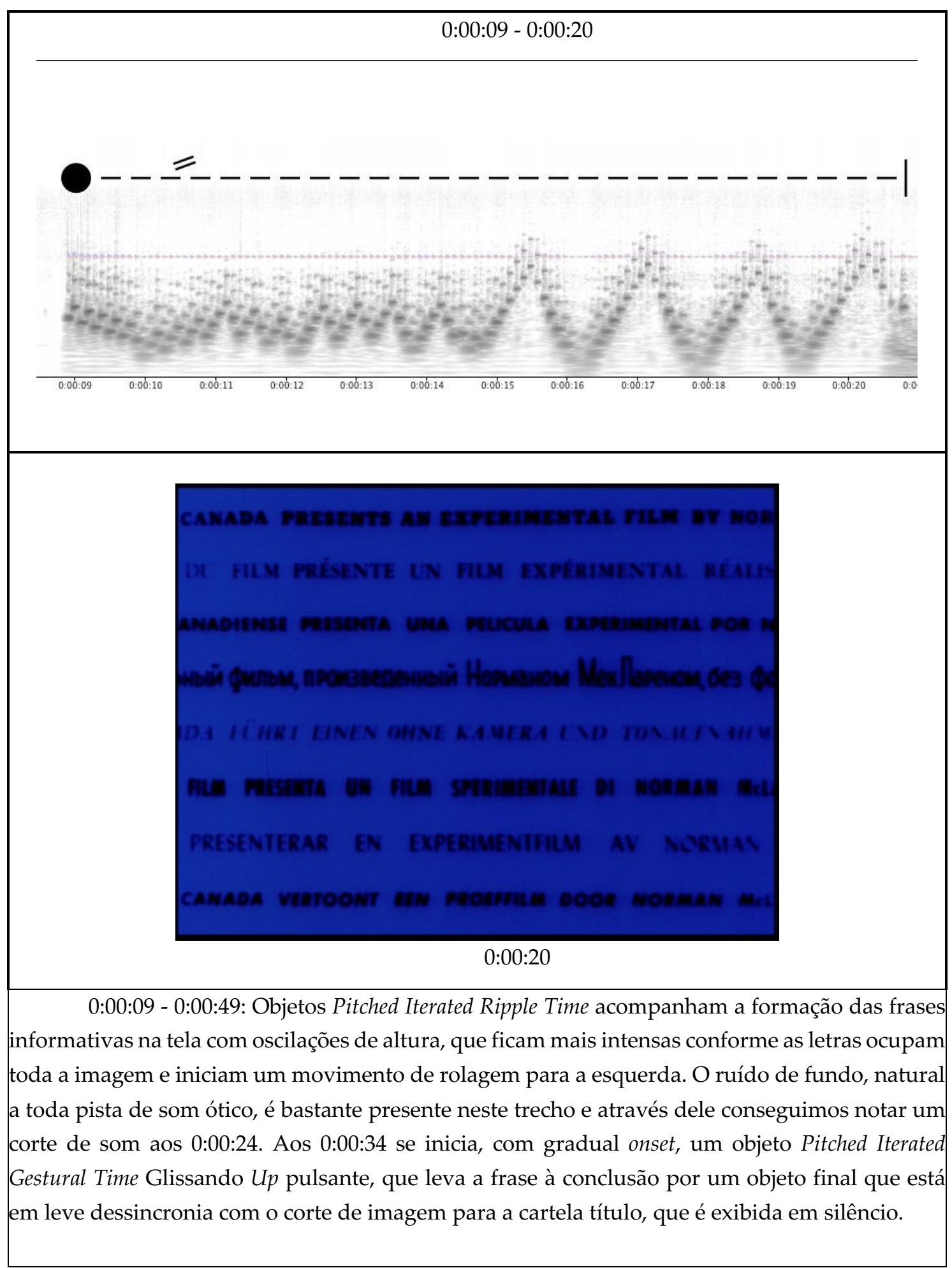


MUSICA THEORICA Revista da Associação Brasileira de Teoria e Análise Musical 2019, v. 4, n. 2, p. 208-228 - Journal of the Brazilian Society for Music

Theory and Analysis @ TeMA 2019 - ISSN 2525-5541

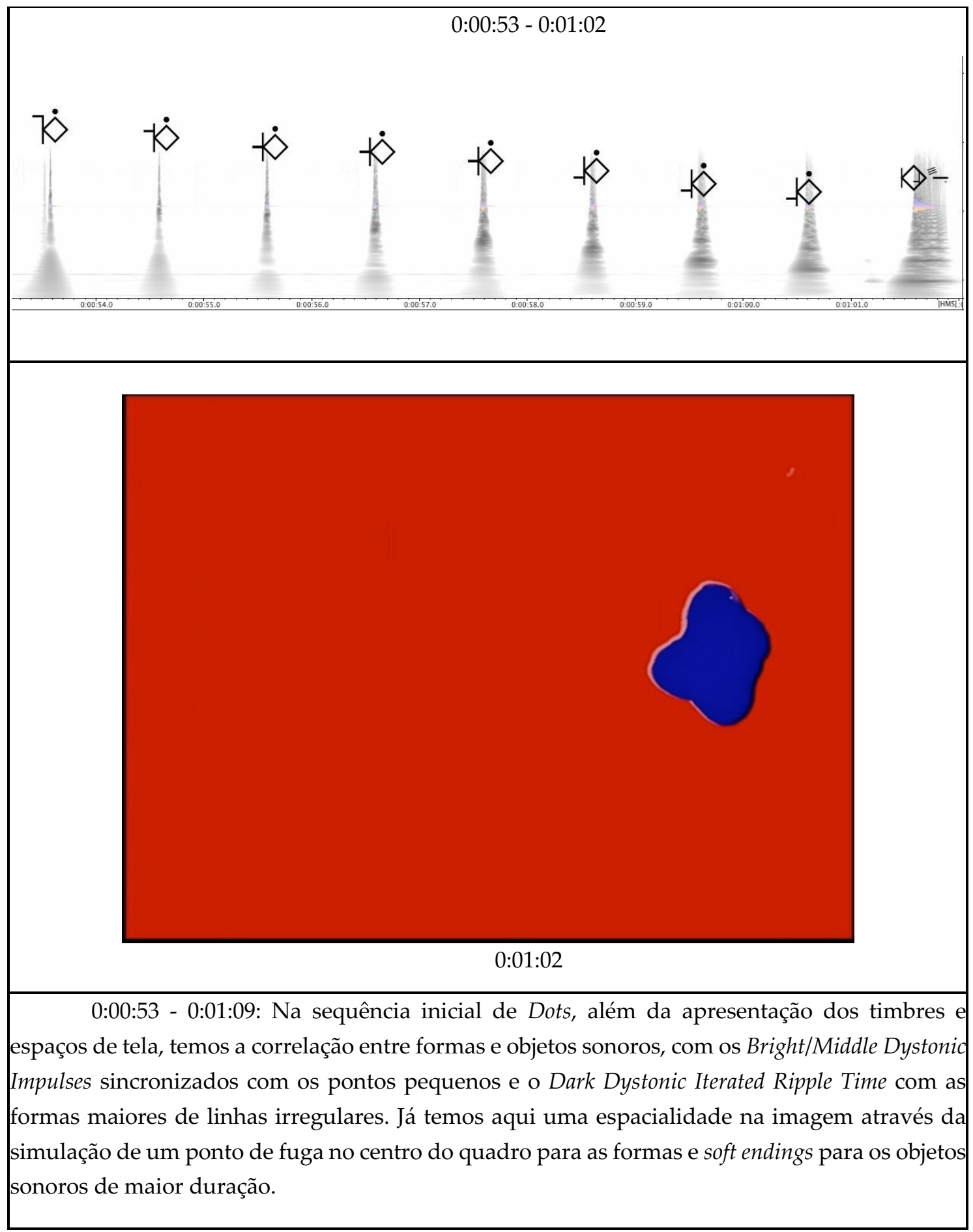




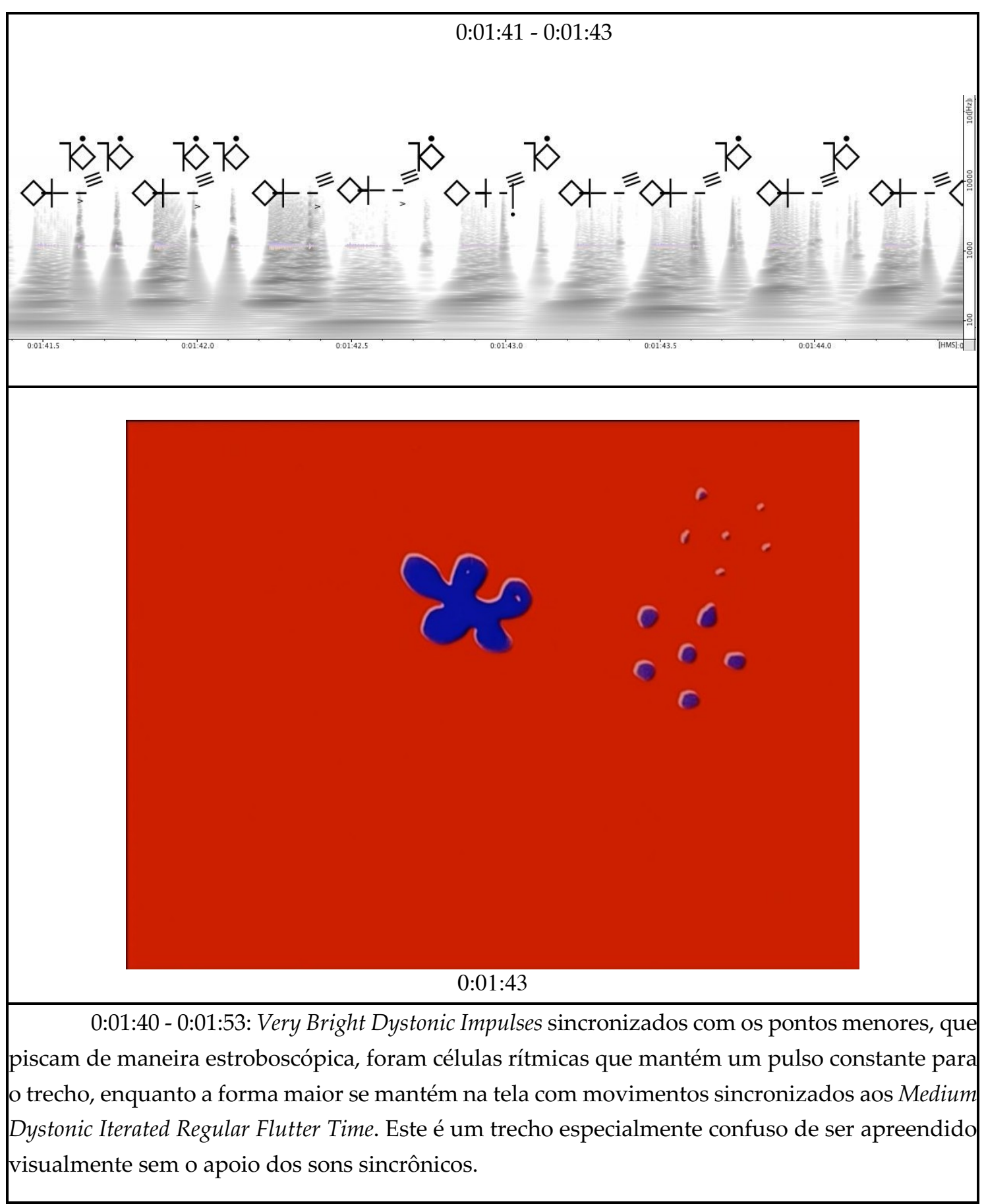


MUSICA THEORICA Revista da Associação Brasileira de Teoria e Análise Musical 2019, v. 4, n. 2, p. 208-228 - Journal of the Brazilian Society for Music

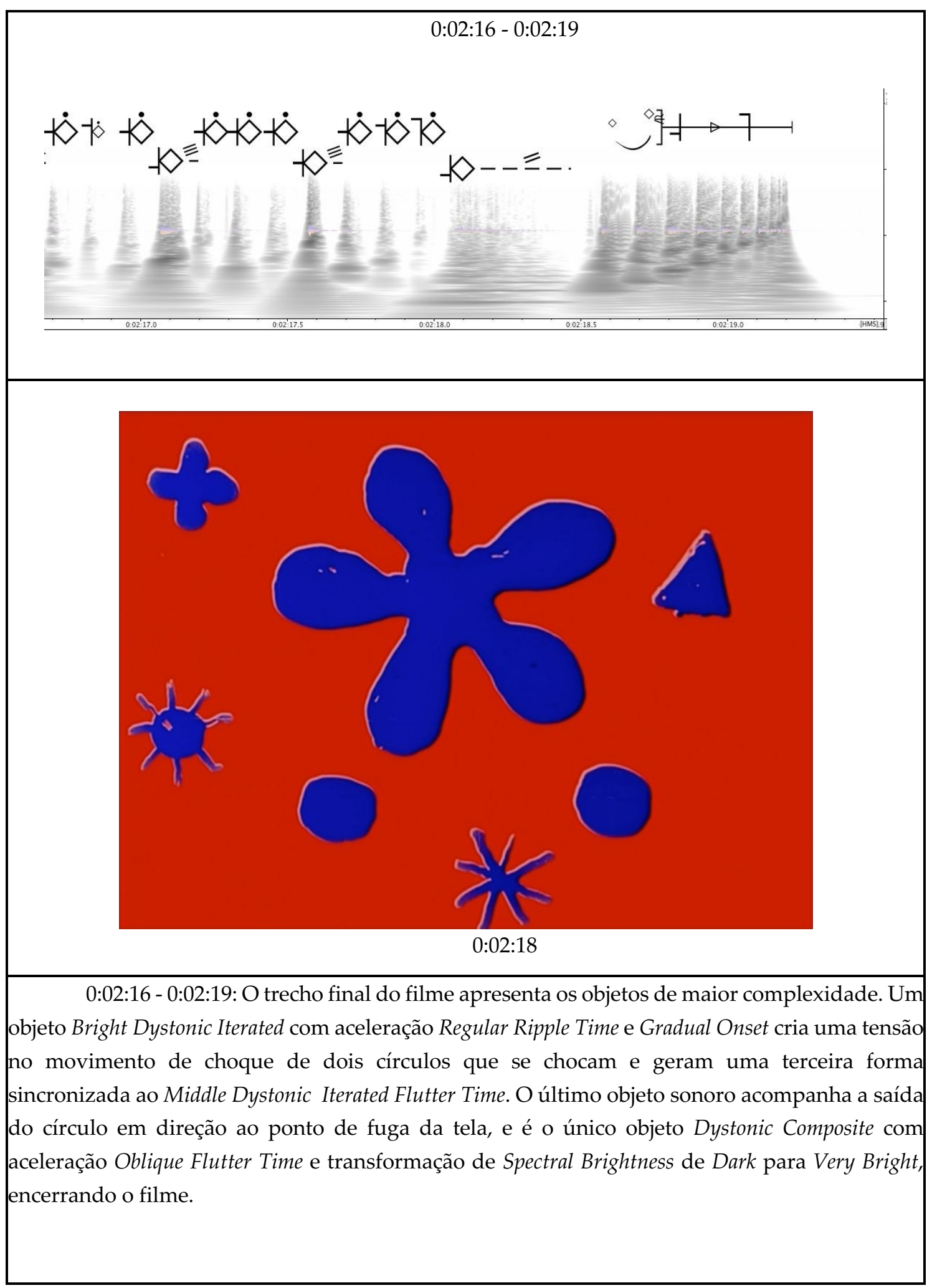




\section{Referências}

1. Chion, Michel. 1994. Audio-Vision. Nova York: Columbia University Press.

2. Chion, Michel. 2009. Film, A Sound Art. Nova York: Columbia University Press.

3. Dobson, Terence. 2006. The Film-work of Norman McLaren. Bloomington: Indiana University Press.

4. James, Richard S. 1986. Avant-Garde Sound-on-Film Techniques and Their Relationship to Electro-Acoustic Music. In: The Musical Quarterly, Vol. 72, No. 1, Oxford University Press.

5. Menc: The National Association for Music Education. 1968. The Handwritten Sound Track. In: Music Educators Journal, Vol. 55, No. 3, Nov., Sage Publications, Inc. p. 114.

6. Mclaren, Norman. 1976. Animated Sound on Film. In: Russet, R.; Starr, C. (Org.). Experimental Animation: An Illustrated Anthology. Nova York: Van Nostrand Reinhold, p. 166-169.

7. McWilliams, Donald (org.). 1991. Norman McLaren on the Creative Process. Montreal: National Film Board of Canada.

8. Russett, Robert; Starr, Cecile (org.). 1976. Experimental Animation: An Illustrated Anthology. Nova York: Van Nostrand Reinhold.

9. Smalley, Denis. 1997. Spectromorphology: explaining sound-shapes. In: Organised Sound 2(2), p. 107-126.

10. Thoresen, Lasse. 2007. Spectromorphological analysis of sound objects: an adaptation of Pierre Schaeffer's typomorphology. In: Organised Sound 12(2): 129-141. Cambridge University Press.

11. Thoresen, Lasse. 2015. Aural Sonology: Emergent Musical Forms. Disponível em: www.auralsonology.com/the-signs/chapter-4-spectromorphology. Acesso em: 2020-01-09.

12. Weis, Elisabeth; Belton, John (org.). 1985. Film Sound: Theory and Practice. Nova York: Columbia University Press. 